Peer-Reviewed Article

ISSN: 2162-3104 Print/ ISSN: 2166-3750 Online

Volume 7, Issue 3 (2017), pp. 786-805

(c) Journal of International Students

http://jistudents.org/

doi: 10.5281/zenodo.570034

\title{
Instructional Practices Facilitating Cross-National Interactions in the Undergraduate Classroom
}

\author{
Diana N. Yefanova \\ Mary Lynn Montgomery \\ Gayle A. Woodruff \\ Christopher J. Johnstone \\ Barbara Kappler \\ University of Minnesota, USA
}

\begin{abstract}
We examine pedagogical practices that facilitate international and domestic students' interactions on two campuses of a U.S. public university. Findings highlight the central role of the instructor in supporting student interactions via pair and group work and collaborative assignments that result in increased understanding of class content. The study highlights the need to intentionally address learning outcomes of cross-national interactions, such as communicative and intercultural skills, as students did not always view the benefits of such interactions in the same way as their instructors did.
\end{abstract}

Keywords: campus internationalization, domestic-international student interaction, internationalization of the curriculum, pedagogy

Recent studies indicate that interaction between domestic and international students in the university classroom, when nurtured and facilitated, offers opportunities for all students' development and learning (Deardorff, 2006; Mestenhauser, 2011; Parsons, 2010). However, clarifying the pedagogical approaches to facilitating cross-national interactions (CNI) has not been the subject of extensive research. For the purpose of this study, we define CNI as interactions that happen between domestic and international students and feature a degree of "discussion and exchange of ideas and perceptions" (Luo \& Jamieson-Drake, 2013, p.86). This study focused on the impact of interactions between international and domestic students in the undergraduate classroom and how instructors leveraged international diversity in their undergraduate classrooms to support intercultural 
awareness and content learning.

Cross-national interactions in higher education institutions are the result of global mobility (i.e., the increasing presence of international students in university classrooms) and pedagogies that privilege interaction and dialogue in the classroom. In our previous research on the educational impact of international students in campus internationalization (Authors, 2014), we examined the potential benefits of CNI as perceived by students. One of our findings pointed to the importance of instructors shifting course design and pedagogical strategies in order to enhance learning for all students - domestic and international. For the second phase of our two-year research project we followed three instructors at the same university into the classroom to better understand their teaching philosophies and practices in relation to cross-national interaction.

This study builds on work focused on the pedagogical aspects of curriculum internationalization (Leask, 2009). Specifically, these aspects refer to the incorporation of an international and intercultural dimension into the content of the curriculum as well as the teaching and learning processes that are responsive to learners from multiple national backgrounds (Jones \& Killick, 2013). Ultimately, the process that university instructors use to adjust course delivery, pedagogy, and content can improve domestic and international student interaction within a learning environment, as studies in the U.S. and Australian context have indicated (Arkoudis et al., 2010; Lee, Poch, Shaw, \& Williams, 2012).

Cross-national interaction is reported to promote intercultural awareness (Leask, 2009) and leadership skills (Luo \& Jamieson-Drake, 2013). To this end, an awareness of CNI is timely for any classroom that: 1) has a multi-national student body; and 2) has some interactive elements in the curriculum design. When carefully facilitated, CNI is intended to develop students who can effectively and appropriately communicate across cultures, demonstrate awareness of their own cultural identity, and understand content in more complex ways (Bennett, 2009; Deardorff, 2006).

For this study we employed the term "international" to define any student who resides in a country outside the U.S. and studies in the U.S. under the provision of a nonimmigrant visa, and define any student with U.S. citizenship or residency as "domestic". It is important to recognize that international students are a heterogeneous group (Andrade et al., 2009) and, as such, experience varying levels of adjustment in a foreign academic environment.

\section{LITERATURE REVIEW}

\section{Pedagogy and Cross-National Interactions}

Over the past several decades, U.S. higher education has seen a shift from a teacher-centric educational structure, in which the traditional lecture 
dominates, to a more inclusive, student-centered, interactive, and experiential learning environment (Bond, 2003; Lee, Shaw, \& Jie, 2014; Vertesi, 1999). This shift reflects 21st century classrooms designed for the inclusion of diverse learning styles and classrooms that value student experiences in classroom discussion (Guo \& Jamal, 2007; Peelo \& Luxon, 2007). Several authors note the need for instructor facilitation to ensure CNI because undergraduate students tend to work with other students from a similar culture and linguistic background and rarely seek out diverse interactions without being prompted by the instructor (Arkoudis et al., 2010; Meerwald, 2013; Venables, Tan \& Miliszewska, 2013). Further, although intended to be inclusive, such approaches reflect U.S. American cultural values and beliefs and may be alienating students who do not share these beliefs or are accustomed to different styles of teaching (Mestenhauser, 2011).

In our previous study of CNI, instructors indicated that differing levels of English language proficiency, limited time spent on campus due to work and family commitments, and differences in academic priorities and learning experiences may also affect CNI in the classroom because of limited contact outside of class. For a variety of reasons, CNI has great potential, but is challenging in practice (Leask \& Carroll, 2011).

Despite these challenges, there is an emerging literature on crossnational pedagogies. For example, instructors may provide specific and multiple opportunities for students to reflect on the cultural experiences around them, incorporate interaction as part of the course design, link the objectives of intercultural interaction with the course learning outcomes and the assessment process (Berg \& Paige, 2009). Arkoudis et al (2010) identified discussion-based and problem-solving activities as well as group projects as recommended by university faculty and students as structured collaborative activities designed to increase student interactions.

\section{Theoretical Perspectives}

The gaps in literature about CNI may be partially filled with information on peer learning theory (Ryan \& Viete, 2009). For example, Ody and Carey (2013) distinguish peer learning experiences as those that are structured and focused on providing common learning experiences, and are designed to engage students in providing feedback on each other's learning via small groups. An important element of peer learning for this study was instructor intentionality, but the peer learning literature is somewhat limited as it does not directly address culture.

A more appropriate theoretical lens may lie in Personalization theory and the Personalization Model of Intergroup Interactions (Ensari and Miller, 2006), which emerged from contact theory (Allport, 1954). Within this model, interpersonal interactions in the classroom involve common 
goals, self-disclosure, self-other comparisons, and perspective taking that create feelings of familiarity, trust, liking, and friendship (Ensari \& Miller, 2006). Learning activities that follow these criteria may also reduce anxiety, reinforcement of stereotypes, feelings of superiority or inferiority, and prejudice associated with interactions with cultural 'others' (Gudykunst, 2005; Hurtado, 2001; Otten, 2003; Pettigrew, 2008). Therefore, such learning activities allow students gain-desired competencies by interacting with peers from other cultures.

Biggs' (2003) Three Levels of Teaching theory builds on Personalization, intercultural, and peer-learning theory to model learning of international students. Biggs identifies three distinct "levels" of teaching that represent different beliefs that instructors bring to their work with international students. A Level 1 instructor focuses on the minimizing of differences between international and domestic students (teaching as assimilating). For this instructor, international students must assimilate into their new surroundings and academic culture. Level 2 instructor accommodates international students' unique needs see teaching as accommodation and tend to modify their instruction to better serve international students (teaching as accommodating). Finally, Level 3 instructors focus on all students' complex learning needs, which may be culturally informed (teaching in context). This level 3 teaching is also defined by constructive alignment between the elements of curricula (Sanderson, 2006b), such as learning outcomes and learning assessment methods. Level 3 instructor helps students develop the necessary skills and knowledge regardless of the cultural context the learning is taking place in.

Sanderson (2006a) critiqued Biggs' approach because it was too narrowly focused on culture; instead, he advocated for a more cosmopolitan approach that assumes recognition of difference, but also states that such differences may be intersectional or may be understood in a limited way through the instructor's own lens. Sanderson argued that instructors need to purposefully create learning environments for culturally diverse students by adopting a reflective approach towards their own teaching (i.e., "cosmopolitan attitude" towards cultural difference), while recognizing that cultural differences among their students exist and can be engaged in the learning process. Although Biggs and Sanderson differ in ontological understandings of culture, both authors work on the assumption that instructors purposefully create learning environments for culturally diverse students through a reflective approach towards their own teaching. This 'praxis' was the focus of our study. Specifically, we inquired:

1. How do instructors enact their vision of CNI to achieve student learning outcomes?

2. From the viewpoint of both the instructor and students, which learning outcomes did CNI support? 


\section{RESEARCH METHOD}

We selected an instrumental multiple case study research model (Yin, 2009) to help us understand the classroom environment and how it impacted student learning. This approach allowed for an analysis of instructors' course design process and the pedagogic activities they used in class, as we sought to discover the rationales and motivations for instructors' support of CNI in diverse classrooms. After receiving approval by the Institutional Review Board, we studied three undergraduate case study classes at two campuses of a large, comprehensive university system for a duration of one semester. The first campus had over 30,000 undergraduate students, over 16,000 graduate students (including 6,000 international students from 142 countries enrolled at the beginning of the study). The second campus had over 1,800 degree-seeking students, including 75 international students from 20 different countries at the time.

We used purposeful sampling (Patton, 2002) to select the case study sites. The cases chosen represent three different disciplines: Economics, Public Speaking, and Biology. The classes were selected based upon the: 1) presence of at least two international students in the classroom; 2) nomination of instructor from a peer or supervisor; and 3) faculty or instructor commitment to curriculum internationalization (as evidenced by participation in the university's faculty development program to internationalize teaching and learning).

\section{Participants}

During spring semester 2015, we conducted multiple semistructured individual interviews with instructors and focus group interviews with students in the three classes. In total, we interviewed three instructors and faculty members (see Table 1 for detailed instructor characteristics) as well as 21 students, including 8 international students. Additionally, we observed these classrooms once or twice per semester and analyzed course syllabi as well as relevant student assignments, such as peer editing reports or end-of-semester reflection essays (see Table 2). Classroom observations took into account all students in the three case study classrooms. There were 74 students enrolled across all three courses.

\section{Data Collection}

During data analysis, two researchers individually read each transcript and all field notes from the classroom observations and identified data themes relevant to the research questions (see Table 2 for an overview of data sources). Then the researchers wrote memos on the types of instructional approaches students and instructors described as supportive of $\mathrm{CNI}$ and on the perceived learning outcomes and challenges associated with those teaching strategies. 
Table 1: Instructor Characteristics

\begin{tabular}{lllllll}
\hline Case & Subject & Exp & Intl & LOE & Led SA & ITL \\
\hline A & Biology & 12 & No & Minimal & Yes & Yes \\
B & Economics & 25 & Yes & Yes & Yes & Yes \\
C & Public Speaking & 24 & No & Yes & No & Yes \\
\hline
\end{tabular}

Note.

Exp - Years of teaching experience

Intl - Faculty born outside of the U.S.

LOE - Proficiency in a language other than English

Led SA - Experience leading student groups on study abroad trips

ITL - Participation in the Internationalizing Teaching and Learning faculty development program

Table 2: Data Sources

\begin{tabular}{lccccccc}
\hline Case & Total Stud & Inst Int & St Int & FGD & Observ & Syll Rev & Assign Rev \\
\hline A & 14 & 3 & 0 & 2 & 2 & Yes & No \\
B & 40 & 2 & 2 & 1 & 2 & Yes & Yes \\
C & 20 & 2 & 2 & 0 & 2 & Yes & Yes
\end{tabular}

Note.

Total Stud - Total number of students in the classroom

Inst Int - Instructor interviews

St Int - Individual student interviews

FGD - Student focus group discussions

Observ - Classroom observations

Syll Rev - Syllabus review

Assign Rev - Assignment review

Researchers responsible for coding used the memos to code individual and focus group interviews using NVivo, via a combination of inductive and deductive coding. We used pre-existing codes from a previous study (e.g., "planning for interaction", "group work facilitation", etc.) as well as additional codes when we saw new themes and patterns emerging in the data, combining deductive and inductive analysis procedures (e.g., "underrepresentation”, “outside of class work”, etc.) (Bogdan \& Biklen, 1982; Merriam, 2002). For every emergent code, researchers met to discuss and draw conclusions to achieve inter-rater agreement. Finally, we coded all student and instructor responses, and established by consensus main data patterns.

\section{RESULTS}

Three main findings emerged from our study related to CNI. First, we found that all instructors were philosophically committed to cross-national interactions in their classes. Second, we found three different models of designing cross-national interactions, but with common threads related to structure and purpose of interactions. Third, we found that students have their own perspectives on ways to further enhance CNI that may not have been considered by instructors. Details for each of these findings are 
described in the paragraphs below.

\section{Instructor Rationale for Structured Cross-National Interactions in the Classroom}

All instructors expressed that incorporating CNI in their courses would prepare students for future careers and develop their communication skills. Instructors identified for us several student learning outcomes in their syllabi that focused on a) the understanding of how culture and cultural perspectives intersect with the course content, b) the development of an appreciation of cultural differences, and c) the ability to intervene in different situations in culturally appropriate and sustainable ways.

The Biology and Economics instructors verbally stated to their students that CNI during group work in the classroom prepared students for jobs that require interacting across cultural differences. For instance, the Economics instructor shared expectations and a rationale for encouraging CNI among students:

Somewhere I say at the beginning of class that I'll force you [international and domestic students] to sit together....and you're going to learn from each other... I also tell them, the other rationale is that all of you are going to get jobs. And if you want a job you can't be quiet.

For the Public Speaking instructor, the most important learning outcome was that the students develop interpersonal skills and learn to interact across difference, regardless of whether or not it was a crossnational interaction. The instructor worked to develop a sense of classroom community by having students engage with all forms of diversity in the classroom.

The most important thing is that students learn how to be more effective communicators, both in listening and speaking. Because they listen to hundreds of speeches, and I point that out, but what does it take to be an effective listener?

In sum, instructors defined CNI as a means to a greater end - a process that facilitated an intended learning outcome. In all cases, CNI was identified and purposefully integrated into course content. The desired outcomes for students varied from instructor to instructor, but generally focused on the development of intercultural skills, communication skills, or leadership and career skills. In summary, CNI was critical to each of the courses because the instructors saw the value in cross-national interactions between students. This valuing led to concrete structuring of activities, 
which is described in the paragraphs below.

\section{Designing Interactions to Engage International Diversity}

Overall, all three instructors aimed to design learning and teaching activities that required their students to engage with their peers around common academic goals and subject knowledge, though what this collaboration looked like and to what extent it was deemed effective by their students varied a great deal from case to case. Despite differences, some common themes emerged in all classes. Each instructor introduced peerlearning activities, set expectations regarding peer interaction, and provided group and pair work resources.

Sometimes domestic and international students worked together strictly to master the course content. Other times they had more of an opportunity to share their unique cultural perspectives with each other and reflect on those differences. One student reacted to this structure:

Yeah, I think [Instructor] is doing a great job, because he wants us to work with each other...And I think that's great. If he just came here and gave out the lectures, maybe we'd never get to know each other. But [the instructor] makes sure we interact and work in groups.” (Biology, international student)

... I used to go to the main (university campus). And it was very different from...the way that [the instructor] has incorporated international students into the class, even though this is a small class... And [the instructor] has taken time to make sure that everyone interacts with each other. (Biology, domestic student)

When it came to "discussion-based activities requiring students to share perspectives” (Arkoudis et al., 2010, p. 16), such activities happened more in smaller discussion-based classes (Public Speaking) than in larger and lecture-based courses (Economics and Biology).

Students in all three classes were tasked with working with another student or a group of students to complete an assignment. In all cases, participant instructors encouraged their students to move out of their regular social groups and interact with each other as much as possible, especially during in-person class sessions.

Instructors planned for the needs of non-native English speakers (both domestic and international) in their courses as they provided support to these students during one-on-one mentoring and providing options for reading the class materials prior to the class in order for students to learn the new vocabulary. Domestic students also came to the classroom with differing levels of "readiness" for CNI, and instructors mentioned having 
occasional one-on-one "interventions" to help boost student confidence and comfort levels with CNI and reduce anxiety.

Table 3: In-Class Learning Activities Supporting CNI

\begin{tabular}{|c|c|c|c|}
\hline & CNI Cluster & Task & $\begin{array}{l}\text { Group } \\
\text { Assignments }\end{array}$ \\
\hline $\begin{array}{l}\text { Case A } \\
\text { (Biology) }\end{array}$ & groups, pairs & quiz prep, simulations & $\mathrm{n}$-a, assigned \\
\hline $\begin{array}{l}\text { Case B } \\
\text { (Economics) }\end{array}$ & pairs & class work, peer editing & $\begin{array}{l}\text { by seating, } \\
\text { assigned }\end{array}$ \\
\hline $\begin{array}{l}\text { Case C (Pub. } \\
\text { Speaking) }\end{array}$ & groups, pairs & discussions, group pres. & $\mathrm{n}-\mathrm{a}$ \\
\hline
\end{tabular}

Students and instructors reported that some of the cross-national interactions took place outside of class (such as a peer-editing assignment in Economics), but most collaborative activities occurred in class, such as group quiz prep and simulations (Biology), group presentation and discussion (Public Speaking), and paired problem solving and discussion (Economics). From the instructors' perspective, group work was a chance for students to learn to work together and share with their peers. Instructors also planned for opportunities for students to reflect on their intercultural learning. However, the extent to which reflection was integrated into the course, and ultimately assessed for student learning or evaluated for a grade, varied markedly. Instructors shared with us their students' responses to several reflection activities, such as the Public Speaking students' reflections on peer critiques of their speeches during the end-of-semester graded reflection assignment. In contrast, the Economics students had one mid-semester opportunity to reflect on their interactions (a written response to the peer editing activity) that was not graded nor followed by similar assignments. Class assignments in the Biology class did not directly prompt students to consider the varying cultural perceptions on the course topic encountered during students' group and pair work. Even when the instructor considered addressing CNI in the end-of-semester learning portfolio or self-reflection assignments, assessing the link between culture and the content was challenging, and the Biology instructor chose not to provide written or oral reflection opportunities for students:

Well to be honest with you, these ideas of appreciation and value [of cross-national interactions]...I don't have a better idea of it other than the self-reflection and the learner portfolio. I can test them on the nuts and bolts of the topic, but to sort of get to these other outcomes, I haven't figured out a way other than that.

In another example of student learning assessment, the peer editing activity in Economics, which was the only structured cross-national 
interaction in the course, was not formally evaluated for a grade. The group quizzes in Biology and the group speech in Pubic Speaking were evaluated for grades, but students did not have to "consider or compare different perspectives on content” (Arkoudis et al., 2010, p. 11) to successfully complete the assignment, nor was this cross-national interaction included in the evaluation of the writing assignment. In the end, Economics and Biology instructors acknowledged the CNI outcome assessment challenge they faced.

No, I've never specifically taught to the student learning outcome...I know that they're getting something out of it ...I did notice that the students interacted really well...they actually were working as a cooperative group. (Economics, faculty member)

If I really wanted to get cross-cultural communication, I don't feel like I've attained that at all. I do think getting students to speak with one another that's not sort of in their self-determined groups, I do think there's a benefit... But I don't think that the content of the course was necessarily tied directly with that effort...I didn't look at that. (Biology, faculty member)

These instructor comments exemplify the tension between wanting to provide students with an opportunity to reflect on culture, and the difficulty to find a connection between culture and academic contact. An overall theme was there was structured thinking about culture in all three classes, but the relative role of reflection and identification of the cultural issues associated with CNI was a challenge to seamlessly integrate into class content.

\section{Cross-National Interaction Effectiveness: Students' Perspectives}

The previous two sections reported on the intentionality and dilemmas that faculty members faced in relation to supporting CNI. These intentions and activities were driven by the instructor's perception on future global workforce needs of students and the desired outcomes that would help students be successful in this environment. Student perspectives on instructors' activities and CNI outcomes indicated that general buy-in around CNI for students and instructors was somewhat complicated by differing perceptions on how to best make CNI work. Overall, although each class was different, student data indicated that students would like to learn from others but did not necessarily have the capacity or motivation to overcome the ambiguity or perceived stress to seek out this learning. At the same time, students felt that because their instructors created expectations related to understanding different cultures' and perspectives on course 
content, that a positive tone was set from beginning of the semester.

For international students, the impact of group work aimed at CNI had practical implications. Far from lofty intercultural dimensions of learning, several students reported enjoying CNI activities because the activities supported content and language learning. Students appeared to be most motivated with CNI activities aligned with course learning outcomes and supported by explicit instructor expectations or grade assignment. Ultimately, all interviewed students expected more immediate outcomes they could apply to own learning, reflecting the perceived utility of interactions described in previous research (Dunne, 2009).

... I think, for overall effect it's very important to have diversity in Econ classes especially because when...you work with other students from other countries in your projects, in your papers, they can contribute more important ideas, which can really help you to learn more thoroughly about your subject. (Economics, international student)

In lecture-based, fast-paced courses (Biology and Economics), international students recalled multiple opportunities for in-class interaction and noted this was a helpful way to share knowledge with each other. At times these students craved more time to work through ideas and to communicate in a way they felt was effective. This learning sometimes happened within international student discussions, demonstrating that CNI may also occur across students from different national backgrounds:

I learned evolution by memorizing...but I came here and I learned evolution and they consider other process and... one of my classmates from Sri-Lanka and he learned about evolution in different ways, so we can kind of share ideas together. (Biology, international student)

At the end of the semester, domestic and international students across the case study classrooms made multiple suggestions as to ways to incorporate more structured interaction opportunities into the course. Although pair and group activities such as quizzes were frequent, students contrasted the lecture-based class style with their more collaborative labbased classes.

I think [the instructor] should have picked groups to place students outside of their comfort zone. She just picked one of the international students [per group]...mine are all domestic students... it would be a good idea to expose everyone at once a semester. 
(Public Speaking, domestic student)

...It would be really interesting to know others' viewpoints on how international students may think about [class topic], and it may help me understand it in different way. It seems that the way that we learn in this [classroom] is just by taking quizzes more independently rather than working together. (Biology, domestic student)

Macro-level, semester-long implications were further informed by student perspectives on day-to-day activities in their classes. Some international students wished that their instructors had asked them to share their perspectives in class more often, but they also did not want to be seen as representing their entire country or culture. In turn, instructors were hesitant to call out international students disproportionately more often and "put them on the spot" during in-class group and pair work and had to find the delicate balance between encouraging international students to share their knowledge and not making students feel uncomfortable. This finding demonstrates another challenging dilemma for CNI. Instructors desired a multiplicity of perspectives, but feared making students uncomfortable. International students were interested in sharing, but feared over-reaching their capacity to represent viewpoints other than their own.

Instructors' delicate balance between expecting verbal participation and honoring students' need for quiet reflection was validated by several students. One student said “I don't like to volunteer. I can't speak for [all students with similar heritage], it is very uncomfortable to volunteer (Public Speaking, international student).

\section{English Language Proficiency: Real and Perceived Barriers to CNI}

Student language capacity was an area that was carefully considered by instructors, but appeared to be of less importance for students. Instructors viewed language barriers as one of the greatest challenges to CNI and considered either domestic students not willing nor able to communicate effectively with non-native speakers of English or international students not having a high enough proficiency level in English to fully participate in the class. The Biology instructor believed that language skills more than any other factor determined students' participation in the class.

I have a Brazilian student who speaks quite well, and I also have a Sri Lankan student that speaks quite well...They interact quite well with other students, it's specifically the Korean students who don't feel quite comfortable.. And I don't think that's a cultural thing so much as just the basic language issue. (Biology instructor) 
In contrast, domestic students downplayed language as a deterrent to cross-national interactions. Several domestic students felt that the lack of international students' full proficiency in English was compensated by international students' efforts to improve their English skills. Others believed that the use of technology to complete assignments together overcame any challenges presented by language.

... I would say the language barrier isn't like a very huge aspect ... it's more the knowledge because of the different teaching styles of the different countries because you know different things. So you could be talking about something with a very intense vocabulary about it and they wouldn't understand. (Biology, domestic student)

Some international students also downplayed the role of language in the classroom, especially in the Economics classroom case study, arguing that it was a math-heavy course, which required less than perfect English proficiency. Despite these challenges, both instructors and students noted there was potential intercultural learning inherent in classroom interactions. This learning was subtle, as this student's reflection notes:

I kind of feel the same way. I went to high school that was, like 99.9\% white... And I feel since I've come...my perspective on things has widened so much from people from different areas, from international students, and you just have a new take. (Public Speaking, domestic student).

Student perspectives indicated that CNI was an important aspect to their learning. For students, the perceived gains from CNI were more immediate - better understanding of content and gatherings of new perspectives on course ideas. The immediacy of goal orientation for students differed somewhat from their instructors, who structured CNI as a way to gain lifelong intercultural skills.

Students overall appreciated the opportunities, and hoped their instructors would provide ways for students to learn from each other. Instructors were at times hesitant to put too much linguistic pressure on students in small and large-group discussions. Such sensitivity aligned with comments from some international students, but not all.

\section{Summary}

In all case studies, instructors purposefully included opportunities for CNI in their classes through an array of grouping strategies, conversational supports, and in some cases reflection activities. Specific 
approaches varied in how students were paired or placed into groups and how tasks were assigned to students, but all were designed to promote group learning across internationally diverse teams. Domestic and international students reported a range of intended and unintended outcomes. For some, CNI facilitated learning course content and intercultural skills. Other students commented that what can be gained from CNI largely depends on student effort.

In general, students minimized several of the barriers described by instructors, such as language barriers, and focused largely on the concrete academic outcomes. They did not experience intercultural learning to the extent envisioned by their instructors, but viewed CNI in the context of immediate content learning. Further, some students indicated that resistance to CNI existed for some domestic and international students. Finally, the delicate balance between a genuinely participative discussion and lines of questioning that appeared tokenistic or artificial appeared to be a significant challenge for both students and instructors in the study.

\section{CONCLUSIONS AND IMPLICATIONS}

This study was built on the premise that, if properly structured, the integration of cross-national interactions in the classroom may help increase academic content learning and intercultural learning of both international and domestic students. To an extent, we found this premise to be present in the data, and learned that instructors employ a variety of strategies. Our pursuit to understand the processes and approaches constructed by instructors to support CNI was complicated by the differences in instructor and student participants' views of outcomes achieved, and yet we did learn ways in which the outcomes and pedagogy were linked.

On the one hand, all three case study instructors worked to create an environment that was conducive to cross-national interactions. On the other hand, interview data also indicated that instructors and students might see the outcomes and goals of CNI differently. Ultimately, students' appreciation of the benefits of CNI and their perceptions of their own learning were connected to the instructors' ability to provide students with rationale for working towards common goals with diverse "others". In addition, students' perception of learning as a result of CNI was also contingent on a) the opportunities to reflect upon various perspectives in the classroom; b) opportunities to link structured CNI to specific learning outcomes and grades; and c) students' own willingness to engage in class interactions.

In general, our findings indicated three important considerations for practice. First, that intentionality pays dividends. Our instructors who planned for, and carefully structured CNI appeared to recognize the greatest benefits from such interactions. Students noted that it is sometimes difficult 
to simply start working in groups, and the most effective strategy reported was clear grouping strategies with concrete outcome expectations. The finding that students discussed their desire for more interaction in small groups and expected instructors to frame the interactions also reflects a certain dependency on the faculty exhibited by students.

Second, students' aspirations for CNI are far less futures-oriented than faculty. While instructors may want to use CNI as a mechanism for creating global citizens, students' focus is primarily on content learning and new perspectives related to such content. To this end, future goals are still an important rationale for CNI, but students may be more receptive if the aim of CNI in class is relevant to intercultural understanding of class content, not generalized cultural development. Finally, open lines of communication between faculty and students are essential. We found numerous perspectives on language, verbal dialogue, and agency in class. Although some perspectives in this study were driven by culture and English as a Second Language status, our interviews and observations indicated that individual learners each come with a set of expectations and aspirations that are and are not informed by cultural or national heritage. To this end, Biggs' (2003) "Level 3" approach to understanding learners may be more effective than a simple domestic/international dichotomy. Such understanding of students may enhance learning for all students, and may also enhance the possibilities for CNI (among other peer learning configurations).

While the descriptive cases presented here represent three unique classrooms as well as a range of course designs and teaching styles, these study results cannot be generalized to a larger population. Instructors were purposefully selected for this study based on their interest and experience in internationalizing their teaching. The fact that we did not speak with an equal number of international and domestic students and that students selfselected to participate in the focus groups means that we may not have heard all students' perspectives in these interviews. Furthermore, information about how instructors incorporated CNI in their class and how students engaged with these activities was largely self-reported.

In this study, CNI outcomes were most often viewed by students through the lens of utility (Dunne, 2009) for academic or professional goals, and its outcomes were most often described generally as positive, interesting, enriching, and valuable. To further understand the dynamics of CNI in undergraduate U.S. classrooms, we need to study factors affecting successful interaction over a period of time (i.e., throughout students' academic career in college, not just one isolated classroom experience).

In addition, the majority of international students in this study were from East Asia (predominantly Korea and China), reflecting the overall international student population at many large public universities in the U.S. It is possible that inviting more international students from other 
backgrounds to participate in this study would have resulted in different accounts of the classroom experience.

Lastly, we observed each class two or three times during the semester. These observations gave insight into classroom interactions and instructional practices, but additional observations would have allowed for an even better understanding of the classroom dynamics at play in each context. A major question remains regarding how to measure cross-national interaction in the classroom.

\section{FUTURE STUDIES}

This study supports research that demonstrates the importance of "belonging" as a factor to consider in fostering cross-cultural interaction and enhance academic performance (Glass \& Westmont-Campbell, 2014). We must acknowledge that, despite instructor support, international and domestic students' experiences with CNI are complex and varied. In this study, all three instructors used formative assessments to allow students to assess their learning in a low-stakes format, but these assessments were not done in a systematic way. Future studies could address the use of such formative assessments to determine students' learning and growth from CNI.

The articulation and assessment of internationalized learning outcomes associated with CNI remains relatively under-reported, and we tend to agree with Jones \& Killick's (2013) conclusion that more studies need to be conducted to examine the achievement of learning outcomes for all students in an internationalized classroom. Another issue that will require sustained attention in the years to come is the alignment of internationalized learning outcomes and related competencies with their assessment in a domestic context and across the years of a program of study. The role of educators in curriculum internationalization via CNI is essential and requires continued transformation of curriculum and educational strategies. We conclude that further research could focus on the role of the teacher and the development of their capacity to design, deliver and assess an internationalized classroom.

\section{REFERENCES}

Allport, G. W. (1954). The nature of prejudice. Reading, MA: Addison-Wesley.

Andrade, M. S. and Evans, N.W. (2009). International students: Strengthening a critical resource. Lanham, MD: Rowman and Littlefield Education.

Andrade, M. S. (2010). Increasing accountability: Faculty perspectives on the English language competence of nonnative English speakers. Journal of Studies in International Education, 14(3), 221-239. 
Arkoudis, S., Baik, C., Marginson, S., \& Cassidy, E. (2012). Internationalising the student experience in Australian tertiary education: Developing criteria and indicators. Centre for the Study of Higher Education.

Arkoudis, S., Yu, X., Baik, C., Chang, S., Lang, I., Watty, K., ... \& Lang, J. (2010). Finding common ground: Enhancing interaction between domestic and international students-Guide for academics. Melbourne, Australia: Australian Learning and Teaching Council.

Authors (2014). Study of the Educational Impact of International Students in Campus Internationalization at the [Institution Name] (Phase 1). Global Programs and Strategy Alliance: University of Minnesota.

Authors (2015). Study of the Educational Impact of International Students in Campus Internationalization at the [Institution Name] (Phase 2). Global Programs and Strategy Alliance: University of Minnesota.

Bennett, M. J. (2009). Defining, measuring, and facilitating intercultural learning: a conceptual introduction to the Intercultural Education double supplement. Intercultural Education, 20(1), S1-S13.

Biggs, J. (2003). Aligning teaching and assessing to course objectives. Teaching and Learning in Higher Education: New Trends and Innovations, 2, 13-17.

Biggs, J., \& Tang, C. (2007). Teaching for quality learning at university. Maidenhead: Open University Press/McGraw Hill.

Bogdan, R. C., \& Biklen, S. K. (1982). Qualitative research for education: An introduction to theory and methods. Boston, MA: Allyn and Bacon, Inc.

Bond, S. (2003). Engaging educators: Bringing the world into the classroom: Guidelines for practice. Ottawa, ON: Canadian Bureau for International Education.

Caffarella, R. (2002). Planning programs for adult learners: a practical guide for educators, trainers, and staff developers (2nd ed.). San Francisco: JosseyBass.

Deardorff, D. K. (2006). Identification and assessment of intercultural competence as a student outcome of internationalization. Journal of Studies in International Education, 10(3), 241-266.

Dunne, C. (2009). Host students' perspectives of intercultural contact in an Irish university. Journal of Studies in International Education, 13(2), 222-239.

Ensari, N. K., \& Miller, N. (2006). The application of the personalization model in diversity management. Group Processes \& Intergroup Relations, 9, 589607.

Gay, G. (2010). Culturally responsive teaching: Theory, research, and practice (2nd ed.). New York: Teachers College Press.

Glass, C. R., \& Westmont, C. M. (2014). Comparative effects of belongingness on the academic success and cross-cultural interactions of domestic and international students. International Journal of Intercultural Relations, 38, 106-119.

Gudykunst, W. B. (2005). An anxiety/uncertainty management (AUM) theory of strangers' intercultural adjustment. In Gudykunst, W. (Ed.), Theorizing about intercultural communication, (pp. 419-457). Thousand Oaks, CA: Sage. 
Guo, S., \& Jamal, Z. (2007). Nurturing cultural diversity in higher education: A critical review of selected models. Canadian Journal of Higher Education, 37(3), 27-49.

Hurtado, S. (2001). Linking diversity and educational purpose: how diversity affects the classroom environment and student development. In Orfield, G (Ed.), Diversity challenged: Evidence of the impact of affirmative action (pp. 187-203). Cambridge, MA: Harvard Education Publishing Group.

Jones, E., \& Killick, D. (2013). Graduate attributes and the internationalized curriculum: Embedding a global outlook in disciplinary learning outcomes. Journal of Studies in International Education, 17(2).

Leask, B. (2009). Using formal and informal curricula to improve interactions between home and international students. Journal of Studies in International Education, 13(2): 205-221.

Leask, B., \& Carroll, J. (2011). Moving beyond 'wishing and hoping': Internationalisation and student experiences of inclusion and engagement. Higher Education Research \& Development, 30(5), 647-659

Lee, A., Poch, R., Shaw, M.A., \& Williams, R. (2012). Engaging diversity in undergraduate classrooms: A pedagogy for developing intercultural competence. Association for the Study of Higher Education Report Series. San Francisco: Jossey-Bass.

Lee, A., Williams, R. D., Shaw, M. A., \& Jie, Y. (2014). First-year students' perspectives on intercultural learning. Teaching in Higher Education, 19(5), 543-554.

Luo, J., and Jamieson-Drake, D. (2013). Examining the educational benefits of interacting with international students. Journal of International Students, 3(2), 85-101.

Meerwald, A.M. (2013). Bridging cultural binaries through pedagogical practices. Brookes eJournal of Learning and Teaching,5(1). Retrieved from http://bejlt.brookes.ac.uk/paper/bridging_cultural_binaries_through_pedag ogical_practices-2/

Merriam, S. B. (2002). Qualitative research in practice: Examples for discussion and analysis. San Franscisco, CA: Jossey-Bass.

Mestenhauser, J. A. (2011). Reflections on the past, present, and future of internationalizing higher education: discovering opportunities to meet the challenges. Minneapolis, MN: Global Programs and Strategy Alliance at the University of Minnesota.

Ody, M.C. \& Carey, W. (2009), Peer assisted study sessions: Personalising the learning experience. In D. Calderon and D. Nutt (Eds.), International perspectives on the first-year experience (pp. 43-48). Columbia, S.C.: University of South Carolina, National Resource Center for the First-Year Experience and Students in Transition.

Otten, M. (2003). Intercultural learning and diversity in higher education. Journal of Studies in International Education,7, 12-26.

Parsons, R. (2010). The effects of an internationalized university experience on domestic students in the United States and Australia. Journal of Studies in International Education, 14(4), 313-334.

Patton, M. Q. (2002). Qualitative interviewing. Qualitative research and evaluation methods, 3, 344-347. 
Peelo, M. \& Luxon, T. (2007). Designing embedded courses to support international students' cultural and academic adjustment in the UK. Journal of Further and Higher Education, 31(1), 65-76.

Pettigrew, T. F. (2008). Future directions for intergroup contact theory and research. International Journal of Intercultural Relations, 32(3), 187-199.

Ryan, J. \& Viete, R. (2009). Respectful interactions: learning with international students in the English-speaking academy. Teaching in Higher Education, 14(3), 303-314.

Sanderson, G. B. (2006a). Examination of a profile of the ideal lecturer for teaching international students (Doctoral dissertation, The Flinders University of South Australia).

Sanderson, G.B. (2006b). And overview of Biggs (2003) Three Levels of Teaching. Retrieved from https://inclusive-teaching.wikispaces.com/Biggs's+work+2

Summers, M. and Volet, S. (2008). Students' attitudes towards culturally mixed groups on international campuses: Impact of participation in diverse and non-diverse groups. Studies in Higher Education, 33(4), 357-370.

Venables, A., Tan, G., and Miliszewska, I. (2013). Developing cross-cultural awareness in IT: reflections of Australian and Chinese students. Journal of Information Technology Education: Innovations in Practice, 12, 91-99.

Vertesi, C. (1999). Students as agents of change. In S. Bond \& J.-P. Lemasson (Eds.), A new world of knowledge: Canadian universities and globalization (pp. 129-158). Ottawa, ON: International Development Research Centre.

Yin, R. K. (2009). Case study research: Design and methods. Thousand Oaks, CA: Sage Publications.

DIANA YEFANOVA, Ph.D., is the Education Program Specialist at the University of Minnesota, Association for Orientation, Transition and Retention in Higher Education. Her research centers on curriculum and campus internationalization as well as cross-border university collaboration. She has worked in the U.S., Russian Federation, and Japan as a researcher, program evaluator, study abroad adviser, university instructor, interpreter, and translator. She is passionate about highimpact, experiential global learning program development in formal and informal education. Email: yefan001@umn.edu

MARY LYNN MONTGOMERY, is a doctoral candidate in Curriculum and Instruction - Second Languages Education at the University of Minnesota. She earned a B.A. in Spanish and French education from St. Olaf College and an M.A. in Spanish from Middlebury College. She has supervised teacher candidates who were pursuing licenses in ESL and World Languages and has taught intercultural communication. Email: mont0269@umn.edu

GAYLE A. WOODRUFF, M.A., is the system-wide director for Curriculum and Campus Internationalization at the University of Minnesota. She founded the University of Minnesota's Internationalizing the Curriculum and Campus initiative, which includes the Mestenhauser Legacy Initiative, the Internationalizing the Curriculum and Campus Conference, and the Internationalizing Teaching and 
Learning Faculty Cohort Program. She has also published on a wide range of topics related to internationalizing higher education. Email: gwoodruf@umn.edu

CHRISTOPHER JOHNSTONE, Ph.D., is an Assistant Professor of Comparative and International Development Education. In his research he explores operationalization of inclusiveness as they relate to both international development, education, and campus internationalization. He has worked on education or development-related projects on every continent except Antarctica, but has primarily focused his research in Sub-Saharan Africa and South Asia. His current projects include studies of livelihoods (Kenya and Tanzania), disability identity (India), and equity issues in internationalization (University of Minnesota). Email: john4810@umn.edu

BARBARA KAPPLER, Ph.D, is the Assistant Dean of International Student \& Scholar Services in the Global Programs and Strategy Alliance. Barbara has 25 years of experience in intercultural communication, program management, teaching, and research. Barbara is also a member of the Graduate Faculty and serves on graduate committees in the department of with the College of Education and Human Development. Barbara is co-author of three guides for students, staff, and language instructors on "Maximizing Study Abroad," as well as a book on communication styles. Her career at the University has been an exciting blend of program and leadership experiences, curriculum development, international communication research, teaching, and working with international students. She has lead a campus focus on using data and research to understand and improve the international student experience. 